
\title{
:
}

eResearch: the open access repository of the research output of Queen Margaret University, Edinburgh

This is an author-formatted version of document published as:

Preston, Chris (2005) Advertising to children and social responsibility. Young Consumers: Insight and Ideas for Responsible Marketers, 6 (4). pp. 61-67. ISSN 1747-3616

\section{Accessed from:}

http://eresearch.qmu.ac.uk/1377/

The published version is available online at:

http://dx.doi.org/10.1108/17473610510701322

\section{Repository Use Policy}

The full-text may be used and/or reproduced, and given to third parties for personal research or study, educational or not-for-profit purposes providing that:

- The full-text is not changed in any way

- A full bibliographic reference is made

- A hyperlink is given to the original metadata page in eResearch

eResearch policies on access and re-use can be viewed on our Policies page:

http://eresearch.qmu.ac.uk/policies.html

\section{Copyright $(9$ and Moral Rights for this article are retained} by the individual authors and/or other copyright owners.

http://eresearch.qmu.ac.uk 
ADVERTISING AND CHILDREN AND THE PARADIGM OF SOCIAL RESPONSIBILITY

\author{
CHRIS PRESTON \\ QUEEN MARGARET UNIVERSITY
}




\begin{abstract}
There is an economic perspective to the paradigm of social responsibility concerning the requirement for children to be socialised into consumers in order to maintain the cycle of consumer expenditure upon which economic health relies. It can be argued that an activity that sustains consumer expenditure is socially responsible.

Advertising is part of the economic socialisation process, as it educates children as to the meanings associated with consumption.

There is however a strong social concern about the effects of advertising upon children, yet there is confusion about exactly what it is that constitutes the problem.

This paper discusses the issues concerning social responsibility and advertising to children, and concludes that whilst younger children do appear to be vulnerable to advertising messages, the thrust of anti-advertising criticism is bound to a mistaken view that advertising is marketing, and an anti-materialist perspective bound to the economic demands of children upon their parents. There is also the issue of advertising that has seemingly not been overtly targeted at children, yet which is received by them.
\end{abstract}




\section{SOCIAL RESPONSIBILITY}

When something is held to be for or against the interests of society, it invariably amounts to a position in relation to a particular view that is held within by a sub-group within society.

Society represents such a diverse multiplicity of sub-groups that it is difficult to consider anything that is in the interests of everyone within it. Economic prosperity appears to be a wide enough benefit to suggest that it benefits society at large, yet it is not evenly distributed, so the benefits are not evenly spread. Notwithstanding this the economic health of a society is generally held to be as near a universal benefit as it is possible to propose.

Any activity that contributes to economic prosperity can therefore legitimately be held to be a socially responsible activity. Moreover, liberty and personal freedom are strongly associated with growth in prosperity (West 1996). The complexity of ethics however renders any activity subject to scrutiny, and an activity that assists the economy of a country, such as arms sales for example, can be held up as not being socially responsible when society is widened to encapsulate all of humanity.

Social responsibility is therefore a many-faceted concept, and should not be blithely applied to a scenario without due care and consideration.

\section{ADVERTISING AND CHILDREN}

The socialisation of children into consumers is necessary given the capitalist system's need for future expenditure. The expenditure approach to the calculation of GDP (Brown 1995) indicates the importance of consumer expenditure to the economy, accounting for around two thirds of wealth

There are however opinions circulated in society at large, by journalism in particular, concerning the ill effects of advertising. If there ethical concerns about the social responsibility of advertising and children, we should be clear as to what they are. If we begin with an account of the marketing and advertising industry, there are certainly questions that can be asked about the extent to which this industry acts responsibly towards the society of children and their parents. 


\section{MARKETERS AND ADVERTISING PRACTITIONERS}

We can be certain that the advertising industry knows a great deal about how children interact with, and react to advertising, with this knowledge based upon experience and research. Given their budget potential one can only surmise that their knowledge is extensive.

Marketers and advertising practitioners keep their knowledge of children's interaction with marketing messages to themselves for competitive and political reasons. No manufacturer or advertiser wishes to publicly portray that they study children's minds, and utilise that knowledge to sell them things, even when that is what they do as a matter of course. This is patently what marketing and advertising to children consists of.

Is this socially responsible behaviour? Like all ethical issues that very much depends on one's point of view. If children are viewed as consumers then basic marketing ideology will involve them being researched in order to be able to market to them more efficiently, thus contributing to the optimisation of consumer expenditure for economic health. If however children are viewed as being worthy of protection from the wiles of commerce through their youth and relative inexperience, then the extent to which they are researched by commercial interests can be held up to criticism.

\section{ADVERTISING'S USE TO CHILDREN}

Children use advertising to learn of the tools of social interaction that will facilitate self-expression and social conformity, both for themselves and their family, and also to find out about the social significance of brands, (Bocker 1986, Cullingford 1984, Belk, Meyer and Driscol (1984).

Children do not have an interest in advertising because of its role in their economic socialisation. There are simple pragmatic reasons for interest. They use it to find out what brands mean, (and sometimes, when an explanation is necessary, what they do, or what they are for). It is very natural to learn of the meaning of things, and the things that most of us come into contact with all the time tend to be things that we buy or have bought for us. 
Advertising explains to children what things mean, things that you can buy and things you can do. Marketed products and activities are closely associated with how children spend their time, and subsequently their behaviour. One particular aspect of the paradigm of social responsibility concerns the appropriateness of such prescribed modes of behaviour given that corporations marketing to children essentially promote behavioural norms, their motivation for doing so being purely profit driven.

Whilst advertising therefore manifestly has an agenda of advocacy, it can be held to perform a social function given the predomination and significance of brand meaning in our materialistic culture. Are children nonetheless being deceived by advertising? It would not be socially responsible for commercial organisations to do so.

\section{$\underline{\text { IS ADVERTISING DECEIVING CHILDREN? }}$}

Chan (2000) reports that by seven and eight years of age children become aware of advertising's persuasive intent, over and above its informational intent. Gaines and Esserman (1981) found that by the age of eight almost all children understand that advertising exists to tell us about things that we may wish to possess, and that few believe advertising to truthful in doing so. Similarly, Martensen and Hansen (1999) found that most eight year old children do not find advertising to be believable. Collins (1990) reported that children only found advertising to be truthful some of the time. Rieken and Yavas (1990) suggest that just as children do not believe a great many advertising claims, they none the less have highly favourable attitudes towards certain of these advertisements.

Children over the age of seven appear to be equipped to deal with advertising, are not naïve about advertising, and are actually quite cynical about its truthfulness. Are such children then vulnerable to advertising? The only way of answering that question is with another question. Are adults vulnerable to advertising? Are adults being deceived by advertising? The question inevitably becomes, is advertising socially responsible, if children by the age of seven or eight are seemingly just as cynical about advertising as one must suppose adults to be. 
Moreover, Belk Meyer and Driscoll (1984) found over twenty years ago that children of nine years and over have developed understanding of the symbolic nature of brand meaning. Is that cause for concern? Is the moral imperative behind criticism of advertising bound to a view that children should not develop materialistic tendencies? Moreover, given the world we inhabit can advertisers be accused of social irresponsibility by suggesting brand meaning through their work? Such a criticism would of course be credible from the point of view of anti-materialist philosophy, yet given the economic imperative for consumer expenditure in the creation of wealth; anti-materialist philosophy could easily be accused of social irresponsibility, as what would be its outcome if enacted?

\section{THE RIGHTS OF YOUNG CHILDREN}

While there is not consensus in the area, there is a general agreement that by the age of five children can meaningfully distinguish television advertising from regular television (John 1999).

There is a general consensus that children below seven or eight are less well equipped to deal with advertising. Clark and Michael (2003) assert that children under the age of eight are exploited by advertising, and Young (1990) proposes that younger children are not as capable of protecting themselves from the pressure it exerts upon their emotional and rational drives.

Verharen (1991) for example found that the use of celebrities and cartoons diminishes younger children's ability to distinguish advertising from programme material. Pine and Nash (2002) found that four to six year old children respond to advertising by requests for advertised toys at Christmas time.

If younger children's behaviour is being influenced by advertising, yet they are not entirely clear as to what advertising is then advertisers can legitimately be referred to the ethics of social responsibility, as a vulnerable section of society is targeted when it can be strongly argued that they should not. It is difficult to conceive of an argument in favour of advertising directly to very young children. 


\section{THE PARENTAL PERSPECTIVE}

Pestering for advertised products is more immediately connected to peer influence than advertising, (Goldstein 1994, Ross 1984), which rather provides a repertoire of potential demand within which peer pressured pestering operates. Importantly, peers operate as both negative and positive reinforcers of advertising messages, (Stoneman and Brody, 1983), and are thus arbiters of acceptability.

None the less, advertised products are demanded with sustained regularity, and can develop to a level of strong importance. For example around half of toy purchases and a third of food and beverage purchases have been reported by parents as nagging driven (Morales 2000).

Advertisers are therefore accused of influencing children's consumption wants in a way that produces peer driven pester power, or to put it another way, it is generating conditions to influence demand.

If parents do not want to be nagged into buying things they perhaps cannot afford or disapprove of, and this is widely agreed to be an issue, then advertising could be approached on grounds of social irresponsibility. As however it has not emerged as an issue that has generated concerted action it remains a tolerated bugbear to disgruntled parents.

Parents feel they are being pressurised by advertisers through the medium of their children, and they very often experience this as an assault upon their finances, and patience. It clouds the waters as to who advertising is held to be directed towards, as children are financially speaking, part of the medium reaching parents, the financiers. If children's apparent desire for merchandise is being constantly deflected, parents may feel guilty about, and frustrated by constant denial. Parents do not generally wish to constantly disappoint their children, and advertising can be viewed as a constant opportunity for them to do so. The issue here then seems to be concerning the right of parents not to be targeted via their children. It can be emotionally disturbing, (Buijzen and Valkenberg 2003), and can lead to financial problems due to the relative ease of obtaining credit. 
As however credit keeps the economy going, it is unlikely that accusations of social irresponsibility by influential bodies representing consumers and poor families will ultimately influence the amount of credit available in the marketplace.

\section{THE SOCIAL RESPONSIBILITY OF FOOD AND BEVERAGE MARKETERS}

Over half of advertisements shown during children's television are for food related products (R.I.P.H. 2003), not to mention viewing at other times. The FSA in collaboration with Strathclyde University (Hastings et al. 2003) gained much publicity for making public children's food preferences are being affected by the advertising of branded nutritionally negative food. The Consumers Association (2003) reported that parents find that marketing (not just advertising) of foodstuffs makes it difficult for parents to provide a healthy diet to their children.

Young (2003) however reminds us that there are many factors to take into account when considering the increase in overweight children, and to single out advertising is unreasonable. To do so also illuminates a fundamental lack of appreciation of the role of advertising within the context of marketing planning. It is surprising that more emphasis does not go on product decisions, such as food composition. As it is the focus persists upon promotional activity.

Many of the food and drink brands advertised with children in mind are deemed unhealthy for reasons of salt, sugar, fat and additive content. Buss (1999) points out that the most successful food and beverage brands consumer by children are adult brands with a wide appeal. These may of course however be advertised with children in mind as a macro audience (Crosier 1999).

The food processing industry is in favour of promoting relatively unhealthy food to children. Of course they have a vested interest in doing so. The question is whether any other body would say that they were in favour of doing so. If the food processing industry is alone in their position then their position regarding social responsibility is unsupported. Never the less they are responsive to consumer demand, and will only make profit from relatively unhealthy food when there are consumers willing to buy it. When children see advertising that is aimed at them, invariably it has been aimed at 
them because marketers have developed a product with a high probability of being agreeable to children.

\section{CHILDREN AS A MACRO AUDIENCE FOR ADULT TARGETED $\underline{\text { ADVERTISING }}$}

The Macro audience for advertising (Crosier 1999) are those to whom the advertising has not been explicitly targeted, yet who are recognised by the advertiser as an inevitable recipient of the message and whose attitudes are taken into account by the advertiser. Are children a Macro audience for adult targeted advertising? Crosier further suggests the Meta audience being those who are not prevented from encountering the advertising. Children certainly fall within this category, and from eight years children encounter more adult orientated advertising than aimed at themselves (Martensen and Hansen 1999).

As to whether children fall within the Macro audience is open to conjecture. Children are entertained by adult advertising (Randrup and Lac 2000) and may count them their favourites (Cullingford 1984). At the same time children have been shown to influence family decision making in a number of markets. For example, $46 \%$ of UK parents reported children's influence upon choice of holiday, 29\% on choice of car, and $15 \%$ on matters relating to home decoration (Mintel 2003).

If children are influential in family purchases and have been recognised by the advertiser then their attitudes will be taken into account. This is just straightforward marketing. Encoding advertising to take into account the attitudes of an audience is a form of targeting. It becomes difficult to define when advertising is aimed at children when they are being taken into account by adult orientated advertisers.

The inconvenience of purchases for themselves demanded by children who may exert a good deal of pressure has become the way advertising's influence has been deemed irresponsible on the whole.

The question of social responsibility and children's advertising has widened of late to include food advertising, yet in this market in particular it is very often difficult to define whether advertisements have been aimed at children, their mother or family, or 
have taken them into account, or at what level they have been incorporated in their inception and production.

If children are therefore sub targets within overtly adult orientated advertising, then the advertising industry can be viewed as designing covert communication aimed at children in order to influence family or adult purchases within the household. There are clearly issues of social responsibility connected with such an activity.

\section{CONCLUSION}

It is all too easy for advertising to be accused of irresponsible influence upon children, yet if the issue is investigated it emerges as an inconsistent position. It is difficult to take seriously that advertising is irresponsible for promoting materialism amongst children. Our society is intrinsically materialist, and advertising is therefore consistent with its context. Within the context of a materialistic society advertising provides a useful function for children by providing information about brands and their symbolic and social meaning. Within that context therefore it can be viewed as socially responsible. It is another question altogether whether materialism is a responsible philosophy to encourage, yet that belongs to another debate.

If advertising practitioners are behaving irresponsibly by researching children for promotional purposes, then the business of marketing must also be considered so, as this is the basis of marketing philosophy and practice. Is it socially irresponsible to apply marketing practice upon children? That very much depends upon one's point of view when it comes to older children, yet with younger children there are clear indicators that research driven marketing to them represents an imbalance of advantage to the marketer.

As the definition of advertising aimed at children is an unsound method of categorisation in many instances, the idea of advertising received by children becomes more useful. If there are concerns about the influence of advertising upon children, and the social responsibility of marketers, the investigation of children's interaction with advertising must approach the issue holistically to account for children's participation of the domestic economy of the family. 


\section{References}

Belk, R, Mayer R, Driscoll, A, (1984), Children's Recognition of Consumption Symbolism in Children's Products, Journal of Consumer Research, Vol. 10, 386-397

Bocker, F, (1986), Children's Influences on their Mother's Preferences, International Journal of Research in Marketing, Vol.3, 39-52

Brown, WS, (1995), Principals of Economics, Minneapolis, West Publishing

Buijzen, M, Valkenberg, PM, (2003), The Unintended Effects of Television Advertising: A Parent-Child Survey, Communication Research, 30, 5, 483-503

Buss, N, (1999), Advertising Food to Children, Dispelling the Myths, International Journal of Advertising and Marketing to Children, 1,1

Chan, K, (2000), Hong Kong Children's Understanding of Television Advertising, Journal of Marketing Communications, Vol. 6, 37-42

Clark, B, Michael, J, (2003), Out of the Mouths of Babes...How Should we be Marketing to Children, Market Research Society Conferences

Collins, J, (1990), Television and Primary School Children in Northern Ireland, the Impact of Advertising, Journal of Educational Television, Vol. 16, 31-39.

The Consumers Association, (2003), Consumer Policy Review, Press Release 26 February. 
Crosier, K, (1999), A Research Based Warning to Advertising Strategists, Conference Paper, Proceedings of the Academy of marketing Annual conference, Stirling.

Cullingford, C, (1984), Children and Television, Aldershot, Gower.

Gaines, L, Esserman, JF, (1981), A Quantitative Study of Young Children's Comprehension of TV Programmes and Commercials, In Esserman (1981c) 95-105

Goldstein, J, (1994), Children and Advertising: Policy Implications of Scholarly Research, The Advertising Association, London.

Hastings, GB, et al. (2003), Report by University of Strathclyde for the Food Standards Agency: The Hastings Report

John, DR, (1999), Consumer Socialisation of Children: A Retrospective Look at Twenty-five Years of Research, Journal of Consumer Research, vol 26, 183-213

Lvovich, S, (2002), Advertising and Obesity: The Research Evidence, The International Journal of Marketing and Advertising to Children, Vol. 4, Issue 2, 3540

Martensen, A, Hansen, F, (1999), Children's Knowledge and Understanding of Commercial Advertising Intentions, Truthfulness and Viewing Habits, Forum for Advertising Research.

Mintel, (2003), Special Report: Selling to and Profiting from Families

Morales, E, (2000), The Nag Factor, Admap,

Pine, KJ, Nash, A, (2002), Dear Santa: The Effects of Television Advertising on Young Children, International Journal of Behavioural Development, 26, 6, 529-539 
Randrup, L, Lac, KT, (2000), Children and TV Commercials, Research Paper, Advertising Research Group, Copenhagen Business School.

Riecken, G, Yavas, U, (1990), Children's general, Product, and Brand Specific Attitudes Toward Television Commercials. Implications for Public Policy and Advertising Strategy, International Journal of Advertising, 9, 136-148

Ross, RP, (1984), When Celebrities Talk Children Listen, Journal of Applied Developmental Psychology, Vol. 5, 185-202.

Royal Institute of Public Health, (2003), The Harben Lecture.

Stoneman, Z, Brody, GH, (1983), Family Interactions During Television Programmes, Journal of Family Issues, Vol.4, 349-365.

Verharen, J, (1991), Kinderen en Televisiereklane, Brussels: Licentiaatsverhandeling, VUB.

West, EG, (1996), Adam Smith into the Twenty-First Century, Cheltnam, Edward Elgar Publishing

Young, B, (1990), Television Advertising and Children, Oxford, Clarendon

Young, B, (2003), Does Food Advertising make children Obese? The International Journal of Marketing and Advertising to Children, Vol. 4, Issue 3, 19-26 